\title{
KONTRIBUSI GAYA KEPEMIMPINAN TRANSFORMASIONAL, ETOS KERJA GURU, KEPUASAN KERJA, DAN BUDAYA ORGANISASI SEKOLAH TERHADAP KINERJA GURU DI SMPK 1 HARAPAN DENPASAR
}

\author{
Siluh Nyoman Princes Oktavia Fairy, I Made Yudana, Dewa Gede Hendra \\ Divayana \\ Jurusan Administrasi Pendidikan \\ Universitas Pendidikan Ganesha \\ Singaraja, Indonesia \\ e-mail: snfairy1980@gmail.com, yudana made08@yahoo.com, \\ doktordivayana@gmail
}

\begin{abstract}
Abstrak
Penelitian ini bertujuan untuk mengetahui: (1) kontribusi gaya kepemimpinan transformasional terhadap kinerja guru, (2) kontribusi etos kerja guru terhadap kinerja guru, (3) kontribusi kepuasan kerja terhadap kinerja guru, (4) kontribusi budaya organisasi sekolah terhadap kinerja guru, (5) kontribusi gaya kepemimpinan transformasional, etos kerja guru, kepuasan kerja, dan budaya organisasi sekolah secara simultan terhadap kinerja guru di SMPK 1 Harapan Denpasar. Populasi adalah semua guru SMPK 1 Harapan Denpasar sebanyak 60 orang. Penelitian ini menggunakan rancangan ex-post facto. Data dikumpulkan dengan kuesioner menggunakan model skala Likert. Teknik analisis data yang digunakan adalah regresi sederhana, korelasi sederhana, korelasi ganda, regresi ganda. Hasil analisis menunjukkan bahwa terdapat: (1) berkontribusi negatif dan tidak signifikan gaya kepemimpinan transformasional terhadap kinerja guru sebesar $-0,185$ dengan sumbangan efektif $-7,15 \%$, (2) berkontribusi positif signifikan etos kerja guru terhadap kinerja guru sebesar 0,58 dengan sumbangan efektif 45,98\%, (3) berkontribusi positif signifikan kepuasan kerja terhadap kinerja guru sebesar 0,09 dengan sumbangan efektif 5,31\%, (4) berkontribusi positif signifikan budaya organisasi sekolah terhadap kinerja guru sebesar 0,15 dengan sumbangan efektif $8,6 \%$, dan (5) berkontribusi yang signifikan secara simultan antara gaya kepemimpinan transformasionaletos kerja guru, kepuasan kerja, dan budaya organisasi sekolah terhadap kinerja guru sebesar 15,39 dengan sumbangan efektif $52,7 \%$. Hal ini berarti keempat variabel tersebut mempunyai kontribusi signifikan terhadap kinerja guru di SMPK 1 Harapan Denpasar.
\end{abstract}

Kata kunci: Gaya Kepemimpinan Transformasional, Etos Kerja Guru, Kepuasan Kerja, Budaya Organisasi Sekolah, Kinerja Guru

\begin{abstract}
This study aims to determine: (1) the contribution of leadership transformational style toward teachers' work performances, (2) the contribution of teachers' work ethos toward teachers' work performance, (3) the contribution of work satisfaction toward teachers' work performance, (4) the contribution of the school organizational culture toward teacher's work performance, and (5) the simultaneous of the contribution leadership transformational style, teachers' work ethos, work satisfaction, the school organizational culture toward teachers' work performance in SMPK 1 Harapan Denpasar. The research is "ex-post facto" with a sample size of 60 peoples. Data were collected by questionnaire and documents. Data
\end{abstract}


analysis was done by using simple regression, multiple regression, and partial correlations. The result showed: (1) leadership transformational style influential in negative and insignificant toward teachers' work performance reaching -0,185 with -7,15\%, (2) teachers' work ethos influential in positive toward teachers' work performance reaching 0,58 with $45,98 \%$, (3) work satisfaction influential in positive toward teachers' work performance reaching 0,09 with 5,31\%, (4) the school organizational culture influential toward teachers' work performance reaching 0,15 with $8,68 \%$, and (5) simultaneously leadership transformational style, teachers' work ethos, work satisfaction, and the school organizational culture influential in positive toward teachers' work performance reaching 15,39 with 52,70\%. This mean the variables has an influence toward teachers work performance in SMPK 1 Harapan Denpasar.

Keywords: leadership transformational style, teachers' work ethos, work satisfaction, the school organization culture, teachers work performance

\section{PENDAHULUAN}

Lembaga pendidikan mempunyai tugas dan tanggung jawab besar dan berat dalam mempersiapkan peserta didik untuk menghadapi kemajuan dunia. Lembaga pendidikan memiliki tanggung jawab untuk menghasilkan peserta didik yang berkualitas, hasil belajar mencapai kriteria yang ditentukan dan siap mengikuti arus perkembangan modernisasi. Lembaga pendidikan tidak dapat dipungkiri merupakan ujung tombak untuk mencapai tujuan-tujuan tersebut, maka lembaga pendidikan harus selalu berbenah, meningkatkan profesionalisme, memiliki fasilitas yang mumpuni, dan memiliki kualitas sumber daya manusia berkualiatas tinggi yaitu tenaga pendidik dan kependidikan (guru), kepemimpinan yang profesional, beserta sarana prasarana yang mampu memfasilitasi kebutuhan peserta didik.

Kualitas guru sebagai tenaga pendidik merupakan salah satu faktor penentu dan memiliki posisi strategis terhadap tinggi rendahnya hasil pendidikan, dan bagaimana kualitas peserta didik memiliki ketergantungan dengan kualitasnya guru sebagai pengajar peserta didik tersebut. Tidak mengherankan jika pemerintah dalam usaha meningkatkan mutu pendidikan Indonesia tidak pernah melepaskan peningkatan kualitas guru, menjadikan guru Indonesia adalah guru yang profesional dengan pelbagai kebijakan strategis yang diterapkan oleh pemerintah. Peran guru dalam pembelajaran yang merupakan proses utama dalam pembentukan pendidikan peserta didik sangat kuat dan merupakan pijakan utama peningkatan kualitas pendidikan. Guru berperan dalam penyusunan desain instruksional, menyelenggarakan proses pembelajaran, dan mengevaluasi hasil belajar peserta didik.

Tugas dan fungsi guru tidak semata memberikan pengetahuan, melainkan membimbing dan memberikan cara peserta didik untuk memecahkan persoalan-persoalan yang dihadapi. Dapat dikatakan bahwa tinggi rendahnya kualitas pembelajaran sebagian besar ditentukan oleh tingkat pelibatan guru dalam proses pembelajaran yang berlangsung dalam lembaga pendidikan/sekolah. Artinya jika guru memiliki semangat dan kinerja yang tinggi terlibat secara penuh dalam proses pembelajaran di sekolah, maka tujuan pendidikan akan dapat tercapai secara efektif dan kualitas lulusan akan meningkat (Sulthon, 2009:5). Figur guru sangat menempati posisi yang strategis dan penting dalam pendidikan, sehingga kinerja guru yang tinggi dan berkualitas adalah hal mutlak untuk terpenuhi.

Salah satu unsur penting dalam upaya meningkatkan kinerja guru menjadi profesional dan berkualitas tinggi adalah kepala sekolah. Pemimpin pembelajaran di sekolah adalah kepala sekolah, maka kepala sekolah akan mencurahkan sebagian besar waktunya bagi pengembangan guru, apabila guru telah mendapatkan perhatian yang lebih dalam proses pengembangan profesinya maka akan meningkatkan kinerjanya. Kepemimpinan pembelajaran sebagai upaya memimpin guru-guru agar proses pembelajaran lebih baik, sehingga dapat memperbaiki hasil belajar peserta didik (Susanto,2016:29). Adanya keterkaitan ini diharapkan dapat membangun dan membentuk suatu situasi yang harmonis sehingga menimbulkan kerjasama yang baik dalam mencapai tujuan sekolah. Untuk itu sekolah memerlukan pemimpin yang reformis, mampu menjadi motor penggerak perubahan 
(transformation) sehingga tercipta kerjasama yang baik antara pimpinan (kepala sekolah) dan bawahan (guru).

Kepemimpinan transformasi atau transformasional adalah kepemimpinan yang mampu mendatangkan perubahan di dalam diri setiap individu yang terlibat atau seluruh organisasi untuk mencapai performa yang semakin tinggi (Susanto,2016:59). Keunggulan kepemimpinan transformasional terletak pada strategi bagaimana mendorong bawahan untuk melakukan usaha yang lebih dari seharusnya (extra effort) sehingga mencapai titik keberhasilan yang memang ditetapkan sekaligus mencapai hasil lebih dari yang ditetapkan. Penerapan gaya kepemimpinan transformasional merupakan pengaruh besar terhadap peningkatan kinerja guru karena dengan gaya kepemimpinan tersebut guru senantiasa didorong melakukan yang terbaik, optimal sehingga menunjukkan kualitas profesionalisme sebagai pengajar dalam dunia pendidikan.

Variabel yang diduga berhubungan dengan kinerja guru selain gaya kepemimpinan adalah etos kerja. Etos kerja guru adalah penghayatan nilai terhadap kerja yang ditunjukkan guru dalam melaksanakan tugas pokok dan fungsinya sebagai pengajar, pendidik, dan pelatih. Guru yang memiliki etos kerja yang tinggi dicerminkan dalam perilaku dan sikap guru yang bercirikan bekerja dengan tulus dan penuh syukur, suka bekerja keras, bekerja benar dan tanggung jawab, kerja tuntas penuh integritas, bersikap adil, tidak membuang-buang waktu selama jam kerja, berkeinginan memberikan lebih dari yang diisyaratkan, mau bekerja sama, hormat terhadap rekan kerja dan bekerja sempurna penuh kerendahan hati. Etos kerja guru tinggi menyebabkan kinerja guru tinggi.

Kinerja guru akan semakin terbentuk jika adanya kompakan antara semua unsur di sekolah.Terbangunnya kerjasama sehingga menimbulkan ciri khas yang dilakukan secara terus menerus dan menjadi landasan falsafah yang didukung oleh organisasi yaitu sekolah. Ini merupakan langkah terbentuknya budaya organisasi sekolah.

Budaya organisasi sekolah yang dianut dan diterapkan oleh sekolah akan mampu mempengaruhi kinerja guru dan pegawai sekolah, karena kinerja guru akan menjadi optimal apabila dintegrasikan dengan komponen persekolahan sehingga menimbulkan loyalitas serta komitment yang tinggi, mampu menyesuaikan diri dari pelbai perbedaan dan perbenturan yang ada agar mampu tetap eksis dan tetap bertahan dengan cara meningkatkan kinerja.

Faktor yang dapat mempengaruhi kinerja guru dan berselarasan dengan etos kerja adalah kepuasan kerja. Kepuasan kerja berhubungan erat dengan adanya rasa percaya dan perasaan positif terhadap karakteristik pekerjaan. Kepuasan kerja pada dasarnya dikembangkan sendiri oleh setiap pekerja atas dasar pekerjaan yang terasa menantang, kondisi pekerjaan yang bagus, imbalan yang berkeadilan, dan adanya peluang besar untuk promosi jabatan atau peningkatan karir. Kepuasan kerja dapat mengurangi tingkat kemangkiran pekerja atau perpindahan pekerja dengan relatif cepat karena terbentuknya solidaritas dan komitmen. Dampak dari meningkatnya kepuasan kerja adalah produktivitas meningkat, komitmen kuat, loyalitas tinggi dan adanya peningkatan kesehatan karyawan karena perasaan nyaman saat bekerja.

Adapun rumusan masalah berdasarkan pemaparan latar belakang diatas yang diajukan dalam penelitian ini sebagai berikut: (1) Seberapa besar kontribusi gaya kepemimpinan transformasional terhadap kinerja guru di SMPK 1 Harapan Denpasar? (2) Seberapa besar kontribusi etos kerja guru terhadap kinerja guru di SMPK 1 Harapan Denpasar? (3) Seberapa besar kontribusi kepuasan kerja terhadap kinerja guru di SMPK 1 Harapan Denpasar? (4) Seberapa besar kontribusi budaya organisasi sekolah terhadap kinerja guru di SMPK 1 Harapan Denpasar? dan (5) Seberapa besar kontribusi gaya kepemimpinan transformasional, etos kerja guru, kepuasan kerja, dan budaya organisasi sekolah secara simultan terhadap kinerja guru di SMPK 1 Harapan Denpasar?

Berdasarkan rumusan masalah yang dikemukankan diatas, maka tujuan penelitian yang diajukan dalam penelitian ini sebagai berikut: (1) Mengetahui dan mendeskripsikan kontribusi gaya kepemimpinan transformasional terhadap kinerja guru di SMPK 1 Harapan Denpasar, (2) Mengetahui dan mendeskripsikan kontribusi etos kerja guru terhadap kinerja guru di SMPK 1 Harapan Denpasar, (3) Mengetahui dan mendeskripsikan kontribusi 
kepuasan kerja terhadap kinerja guru di SMPK 1 Harapan Denpasar, (4) Mengetahui dan mendeskripsikan kontribusi budaya organisasi sekolah terhadap kinerja guru di SMPK 1 Harapan Denpasar, (5) Mengetahui dan mendeskripsikan kontribusi gaya kepemimpinan transformasional, etos kerja guru, kepuasan kerja, dan budaya organisasi sekolah secara simultan terhadap kinerja guru di SMPK 1 Harapan Denpasar.

\section{METODE}

Penelitian dilaksanakan di SMPK 1 Harapan Denpasar dengan menggunakan teknik penentuan sampel dalam penelitian ini digunakan adalah sampling jenuh atau sensus. Teknik ini digunakan jika jumlah populasi relatif kecil. Dikarenakan populasi dalam penelitian ini tidak terlalu banyak, maka seluruh populasi digunakan sebagai sampel penelitian yakni 60 orang, karena jumlah guru di SMPK 1 Harapan Denpasar berjumlah 60 orang guru.

Metode penelitian; analisis deskriptif, pendekatan kuantitatif, teknik analisis dengan korelasi product moment, determinasi dan regresi dengan menggunakan bantuan SPP 17.00 for windows dengan pendekatan penelitian ex post facto. Alat pengumpul data berupa kuesioner, analisis data dengan teknik regresi sederhana, regresi ganda, dan korelasi parsial.

\section{HASIL DAN PEMBAHASAN}

Hasil penelitian yang dimaksud adalah menyangkut gaya kepemimpinan transformasional, etos kerja guru, kepuasan kerja, dan budaya organisasi sekolah terhadap kinerja guru di SMPK 1 Harapan Denpasar. Berdasarkan analisis data dan pembahasan menunjukkan sebagai berikut: (1) kontribusi gaya kepemimpinan transformasional bernilai negatif sebesar $-0,245$, dan setelah diuji secara parsial dengan uji T diperoleh nilai t hitung sebesar $-1,396$, dengan sumbangan efektif sebesar $-7,1 \%$, maka disimpulkan bahwa gaya kepemimpinan transformasional memiliki kontribusi negatif tidak signifikan terhadap kinerja guru di SMPK 1 Harapan Denpasar, (2) kontribusi etos kerja guru bernilai positif sebesar 0,710 , dan setelah diuji secara parsial dengan uji $\mathrm{T}$ diperoleh nilai t hitung sebesar 5,401 , dengan sumbangan efektif sebesar 45,9\%, maka disimpulkan bahwa etos kerja guru berkontribusi positif signifikan terhadap kinerja guru di SMPK 1 Harapan Denpasar, (3) kontribusi kepuasan kerja bernilai positif 0,120 , dan setelah diuji secara parsial dengan uji $\mathrm{T}$ diperoleh nilai t hitung sebesar 0,668, dengan sumbangan efektif sebesar 5,3\%, maka disimpulkan bahwa kepuasan kerja memiliki kontribusi positif terhadap kinerja guru di SMPK 1 Harapan Denpasar, (4) kontribusi budaya organisasi sekolah bernilai positif 0,213 , dan setelah diuji secara parsial dengan uji T diperoleh nilai t hitung sebesar 1,124, dengan sumbangan efektif $8,6 \%$, maka budaya organisasi sekolah berkontribusi positif terhadap kinerja guru di SMPK 1 Harapan Denpasar, (5) melalui uji $F$ diperoleh nilai sebesar 15,395 lebih besar dari nilai $F$ tabel, dengan sumbangan efektif sebesar $52,7 \%$, maka secara simultan gaya kepemimpinan transformasional, etos kerja guru, kepuasan kerja, dan budaya organisasi sekolah berkontribusi positif siginifikan terhadap kinerja guru di SMPK 1 Harapan Denpasar.

\section{SIMPULAN DAN SARAN}

Berdasarkan tujuan penelitian yang telah dilakukan, maka dapat diambil kesimpulan sebagai berikut: (1) Tidak terdapat kontribusi yang signifikan gaya kepemimpinan transformasional terhadap kinerja guru di SMPK 1 Harapan Denpasar, dimana nilai koefisien kontribusi sebesar -0,245 dan diuji secara parsial menghasilkan -1,396 lebih kecil dari T tabel. Variabel gaya kepemimpinan transformasional memberikan sumbangan efektif sebesar $-7,1 \%$. (2) Terdapat kontribusi yang signifikan etos kerja guru terhadap kinerja guru di SMPK 1 Harapan Denpasar, dimana nilai koefisien kontribusi sebesar 0,701 , dan diuji secara parsial menghasilkan 5,401 lebih besar dari $\mathrm{T}$ tabel. Variabel etos kerja guru memberikan sumbangan efektif sebesar 45,9\%. (3) Terdapat kontribusi yang signifikan kepuasan kerja terhadap kinerja guru di SMPK 1 Harapan Denpasar, dimana nilai koefisien kontribusi sebesar 0,120, dan diuji secara parsial menghasilkan 0,668 lebih kecil dari T tabel. Variabel kepuasan kerja memberikan sumbangan efektif sebesar 5,3\%. (4) Terdapat kontribusi yang signifikan budaya organisasi sekolah terhadap kinerja guru di SMPK 1 Harapan, dimana nilai 
koefisien kontribusi sebesar 0,213 dan diuji secara parsial menghasilkan 1,124 lebih kecil dari t tabel. Variabel budaya organisasi sekolah memberikan sumbangan efektif sebesar $8,6 \%$. (5) Secara simultan adanya kontribusi yang signifikan gaya kepemimpinan transformasional, etos kerja guru, kepuasan kerja, dan budaya organisasi sekolah terhadap kinerja guru di SMPK 1 Harapan sebesar 15,395 lebih besar dari t tabel. Variabel gaya kepemimpinan transformasional, etos kerja guru, kepuasan kerja dan budaya organisasi sekolah memberikan sumbangan efektif sebesar 52,7\%. Berdasarkan temuan dalam penelitian ini, secara garis besar menunjukkan bahwa variabel gaya kepemimpinan transformasional, etos kerja guru, kepuasan kerja, dan budaya organisasi sekolah berpengaruh secara positif dan signifikan terhadap kinerja guru di SMPK 1 Harapan Denpasar, ini berarti keempat variabel tersebut merupakan predictor peningkatan kinerja guru di SMPK 1 Harapan Denpasar. Berdasarkan penemuan tersebut, maka disarankan beberapa hal sebagai berikut: 1) memiliki tanggung jawab pribadi yang tinggi, 2) memiliki program kerja berdasarkan program kerja yang realistic serta berusaha untuk merealisasikan, 3) memiliki kemampuan untuk mengambil keputusan dengan hasil yang memuaskan. Kepada kepala sekolah hendaknya lebih mengefektifkan gaya kepemimpinan transformasional terlebih dalam penelitian ini variabel gaya kepemimpinan transformasional memberikan sumbangan negative terhadap kinerja guru, artinya kepala sekolah harus lebih meningkatkan penerapan gaya kepemimpinan ini dengan lebih tepat, lebih mengenali bagaimana cara-cara yang lebih persuasif sehingga tercipta lingkungan sekolah yang lebih kondusif, memuaskan bagi warga sekolah terutama guru, lebih memantapkan prinsip budaya sekolah dan juga mengusahakan berbagai upaya untuk dapat meningkatkan kinerja guru.

Kepada para pengawas sekolah termasuk Yayasan yang menaungi sekolah memberikan kebijakan yang mengarah pada peningkatan sumber daya manusia warga sekolah. Dalam pengangkatan kepala sekolah perlu mengadakan tes kepemimpinan dalam berbagai gaya atau tipe sehingga menemukan gaya yang ideal untuk diterapkan, termasuk bagaimana kepala sekolah bisa memberikan prinsip dasar mengenai etos kerja sehingga bisa berimbas lebih positif terhadap kepuasan kerja maupun budaya organisasi sekolah, dengan tujuan keunggulan dan prestasi sekolah dapat meningkat secara optimal. Di sisi lain perlu melakukan monitoring secara berkala dan lebih terstruktur sehingga faktor-faktor terkecilpun bisa dimonitoring dan dievaluasi oleh para pengawas sekolah.

\section{DAFTAR PUSTAKA}

Agung, A.A. 2014. Metode Penelitian Pendidikan: Pers Manajemen Pendidikan: DIPA Undiksha.

Agung, A.A. dkk. 2011. Menjadi Guru Profesional Yang Tersertifikasi: Upaya Pengembangan Kompetensi Kepribadian, Kompetensi Pedagogik, Kompetensi Profesional, dan Kompetensi Sosial. Singaraja: DIPA Undiksha.

Asmani, Jamal. 2009. Manajemen Pengelolaan dan Kepemimpinan Pendidikan Profesional. Yogyakarta: Diva Press.

Bryson, John. 1995. Strategis Planning for Public and Non Profit Organizations:A Guide to Strengthening and Sustaining Organizational Achievement.Revised Ed. San Fransisco: Jossey-Bass Publishers.

Busro, Muhammad. 2018. Teori-Teori Manajemen Sumber Daya Manusia. Jakarta: Prenadamedia Group.

Candiasa, I Made, 2010. Statistik Univariat dan Bivariat Disertai Aplikasi SPSS. Singaraja: Unit Penerbitan Universitas Pendidikan Ganesha.

Daft, Richard. 2005. Organization Theory and Design, $3^{\text {rd }}$ Ed. USA.

Degeng, Nyoman. 2013. Ilmu Pembelajaran:Klasifikasi Variabel Untuk Pengembangan Teori dan Penelitian. Bandung: Kalam Hidup dan Arasmedia. 
Depdiknas. 2003. Undang-Undang Dasar RI. No 20 Tahun 2003. Sistem Pendidikan Nasional.

Divayana, Dewa Gede. 2017. Buku Ajar Asesmen dan Evaluasi. Singaraja: Undiksha Press.

Fattah, Nanang. 2013. Landasan Manajemen Pendidikan. Bandung: PT Remaja Rosdakarya.

Hasibuan, S.P. 2002. Organisasi dan Motivasi. Jakarta: PT Bumi Aksara.

Herrhyanto, Nar. 2017. Analisis Data Kuantitatif dengan Statistika Inferensial. Bandung: Penerbit Yrama Widya.

Kiswanti, Wahyudi, M.Syukri, 2014."Pengaruh Kepemimpinan Kepala Sekolah dan Iklim Organisasi Sekolah Terhadap Kinerja Guru di SMP Negeri Sub Rayon 4 Pontianak". Jurnal FKIP Universitas Tangjung Pura, Pontianak.

La Sulo, Tirtarahardja. 1995. Pengantar Pendidikan: Proyek Pembinaan dan Peningkatan Mutu Tenaga Kependidikan. Direktorat Jenderal Pendidikan Tinggi Departemen Pendidikan dan Kebudayaan 1994.

Luthans, Fred. 2011. Organizational Behaviour: An Evidence-Based Approach. $12^{\text {th }}$ Ed. New York: McGraw-Hill Irwin.Inc.

Mangkunegara, AA, Prabu. 2000. Manajemen Sumber Daya Manusia. PT Rosda Karya. Bandung.

Marks, James Robert, Sir. 1985. Handbook of Educational Supervision. USA: Allyn and Bacon, Inc.

Mulyasa, E. 2003. Manajemen Berbasis Sekolah Konsep Strategi dan Implementasi. Bandung: CV. Rosdakarya.

Nawawi, H. 1985. Organisasi Sekolah dan Pengelolaan Kelas. Jakarta: Gunung Agung.

Peraturan Menteri Negara Pendayagunaan Aparatur Negara dan Reformasi Birokrasi No.16 Tahun 2009. Jabatan Fungsional Guru dan Angka Kreditnya.

Peraturan Menteri Pendidikan Nasional No. 35 Tahun 2010. Petunjuk Teknis Pelaksanaan Jabatan Fungsional dan Angka Kreditnya.

Peraturan Menteri Pendidikan Nasional Republik Indonesia No.41 Tahun 2007. Standar Proses untuk Satuan Pendidikan Dasar dan Menengah.

Peraturan Pemerintah Republik Indonesia No.19 Tahun 2005. Standar Pendidikan Nasional.

Purwanto, Ngalim. 2016. Administrasi dan Supervisi Pendidikan. Bandung: PT Remaja Rosdakarya.

Robbins dan Judge. 2015. Organizational Behavior, $16^{\text {th }}$ ed. Alih Bahasa oleh Ratna Saraswati dan Febriella Sirait: Perilaku Organisasi -Ed.16-. Jakarta: Salemba Empat.

Sahertian, 1994. Supervisi Pendidikan Dalam Rangka Program Inservice Education. Jakarta: Rineka Cipta .

Santoso, Singgih. 2009. Panduan Lengkap Menguasai Statistik Dengan SPSS 17. Jakarta: PT Elex Media Komputindo.

Schein, Edgar. 2004. Organizational Culture and Leadership. $3^{\text {rd }}$ Ed. San Fransisco: JosseyBass.Inc.

Sedarmayanti. 2000. Manajemen Sumber Daya Manusia: Reformasi Birokrasi dan Manajemen Pegawai Negeri Sipil. Jakarta: Refika Aditama.

Sugiyono. 2012. Metode Penelitian Kuantitatif Kualitatif dan R\&D. Bandung:Alfabeta. 
Sulthon. 2009. Membangun Semangat Kerja Guru: Suatu Aplikasi Pendekatan Emotional Intelligence dan Social Intelligence dalam Manajemen Pendidikan di Sekolah. Yogyakarta: Laksbang Pressindo Yogyakarta.

Sungarimbun, Masri, Sofian Efendi, 2006. Metode Penelitian Survey. Edisi Revisi. Jakarta: LP3ES.

Suparno dan Danim. 2009. Manajemen dan Kepemimpinan Transformasional Kekepalasekolahan: Visi dan Strategi Sukses Era Teknologi, Situasi Krisis, dan Internasionalisasi Pendidikan. Jakarta: Rineka Cipta.

Suryadi, Tilaar. 1993. Analisis Kebijakan Pendidikan. Bandung: PT Remaja Rosdakarya.

Susanto, Ahmad. 2016. Manajemen Peningkatan Kinerja Guru: Konsep, Strategi, dan Implementasinya. Jakarta: Prenadamedia Group.

Terry dan Rue. 1992. Principles of Management. Alih Bahasa: G.A. Ticoalu: Dasar-dasar Manajemen. Jakarta: Bumi Aksara.

Undang-Undang Republik Indonesia No.20 Tahun 2003. Standar Pendidikan Nasional.

Undang-Undang Republik Indonesia Nomor 14 Tahun 2005. Tentang Guru dan Dosen.

Wahab, Abdul Azis.2008. Anatomi Organisasi dan Kepemimpinan Pendidikan: Telaah Terhadap Organisasi dan Pengelolaan Organisasi Pendidikan. Bandung: Alfabeta.

Yudana, Made. 2012. Hand Out Mata Kuliah Manajemen Berbasis Budaya. Singaraja: Pasca Sarjana Undiksha.

Yudana, Made. Orasi IImiah Pengenalan Guru Besar Tetap,4 Desember 2010. Singaraja: Universitas Pendidikan Ganesha.

Yulk, Gary.2009. Leardership in Organization. Alih Bahasa oleh Bud Supriyanto: Kepemimpinan dalam Organisasi -Ed.5-. Jakarta: Indeks 